\title{
TEM (HREM) and STEM (HAADF/EDS) Study of the Metallic Dispersion in Supported Ruthenium Catalysts
}

\author{
J.C. Hernández, D.M. Vidal, A.B. Hungría, S. Trasobares, M.P. Rodríguez-Luque, C. Mira, J.J \\ Calvino and J.A. Perez-Omil
}

Departamento de Ciencia de los Materiales, Ingeniería Metalúrgica y Química Inorgánica. Universidad de Cádiz. Facultad de Ciencias, Puerto Real (Cádiz) 11510 Spain

Noble metals highly dispersed on cerium-zirconium mixed oxide supports are commonly employed as a component in three ways catalysts (TWC) and currently they are tested in catalytic processes for hydrogen production [1]. The dispersion of the metallic phase, defined as the fraction of metallic atoms exposed at the surface, is one of the key parameters determining the behaviour of these catalysts. It is well known that this parameter can be estimated from the analysis of Particle Size Distributions obtained using Electron Microscopy techniques [2].

In this contribution the results of the characterization of ruthenium nanoparticles supported on different oxides $\left(\mathrm{Al}_{2} \mathrm{O}_{3}, \mathrm{Ce}_{0.5} \mathrm{Zr}_{0.38} \mathrm{~Tb}_{0.12} \mathrm{O}_{2,}, \mathrm{Ce}_{0.62} \mathrm{Zr}_{0.38} \mathrm{O}_{2}\right.$ and $\left.\mathrm{Ce}_{0.8} \mathrm{~Tb}_{0.2} \mathrm{O}_{2}\right)$, using high resolution electron microscopy (HREM), high angle annular dark field (HAADF) in scanning-transmission (STEM) mode and X-Ray spectroscopy (EDS), are presented. From these data, the dispersion of the metallic phase is determined. The nano-structural evolution of the catalysts has also been followed after reduction treatments in an atmosphere of $\mathrm{H}_{2}(5 \%) / \mathrm{Ar}$ at increasing temperatures in the range $623 \mathrm{~K}-1173 \mathrm{~K}$.

The analysis of the electron microscopy images of the samples shows the convenience of using HAADF technique in addition to HREM for the characterization of these catalysts. In the case of the $\mathrm{Al}_{2} \mathrm{O}_{3}$ supported $\mathrm{Ru}$ catalysts, HAADF imaging [3] improves the contrast between the metal particles and the support, as compared to HREM. This allows extending the range of measurable particles diameters (figures 1.a and 1.b). For the sample studied in this contribution, the dispersion values calculated from the particle sizes distribution curves obtained by HREM and HAADF are similar, but the use of HAADF increases the reliability of the dispersion values observed for these samples. In the case of the cerium-zirconium supported $\mathrm{Ru}$ catalysts, HAADF images, in combination with EDS spectroscopy, fig. 4, are necessary to avoid misidentification of Ru particles.

The comparative analysis of data summarized in table 1 shows the following results: a) The initial dispersions of the $\mathrm{Ru}$ for the whole set of catalysts studied in this work (with the exception of the $\mathrm{Ce}_{0.8} \mathrm{~Tb}_{0.2} \mathrm{O}_{2}$ supported catalyst) are similar; b) the dispersion of both the alumina and the $\mathrm{Ce}-\mathrm{Tb}$ mixed oxide supported Ru catalysts decreases notably with increasing reduction temperature; c) the dispersion of $\mathrm{Ru}$ does not change significantly for the catalysts based on $\mathrm{Ce}-\mathrm{Zr}$ or $\mathrm{Ce}-\mathrm{Zr}-\mathrm{Tb}$ mixed oxides in the range of temperature studied here. Thus, these results show clearly that the incorporation of $\mathrm{Zr}$ to the cerium oxide or cerium-terbium mixed oxide matrix allows a stabilization of the metallic dispersion. The origin of this effect is a matter of further study at this moment. 
References

[1] S. Bernal et al., Top. Catal. 28 (2004) 31

[2] Special Issue: HRTEM for Catalysis, Catal. Today (3) (1995) 23

[3] S.J. Pennycook et al, Nature. Vol. 336 (1988) 565

[4] We acknowledge the financial support from Ministry of Education and Science of Spain (MAT2002-02782) and Junta de Andalucia (FQM334, FQM110). Electron microscopy imaging was carried out in the Central Service of Science and Technology from Universidad de Cadiz.

TABLE 1. Evaluation of the metallic dispersion with the thermal treatment.

\begin{tabular}{lcc}
\hline Catalyst & Reduction $623 \mathrm{~K}$ & Reduction $1173 \mathrm{~K}$ \\
\hline $\mathrm{Ru}(3 \%) / \mathrm{Al}_{2} \mathrm{O}_{3}$ & 58 & 34 \\
$\mathrm{Ru}(1 \%) / \mathrm{Ce}_{0.62} \mathrm{Zr}_{0.38} \mathrm{O}_{2}$ & 55 & 48 \\
$\mathrm{Ru}(1 \%) / \mathrm{Ce}_{0.5} \mathrm{Zr}_{0.38} \mathrm{~Tb}_{0.12} \mathrm{O}_{2}$ & 57 & 47 \\
$\mathrm{Ru}(1 \%) / \mathrm{Ce}_{0.8} \mathrm{~Tb}_{0.2} \mathrm{O}_{2}$ & 31 & 15 \\
\hline
\end{tabular}
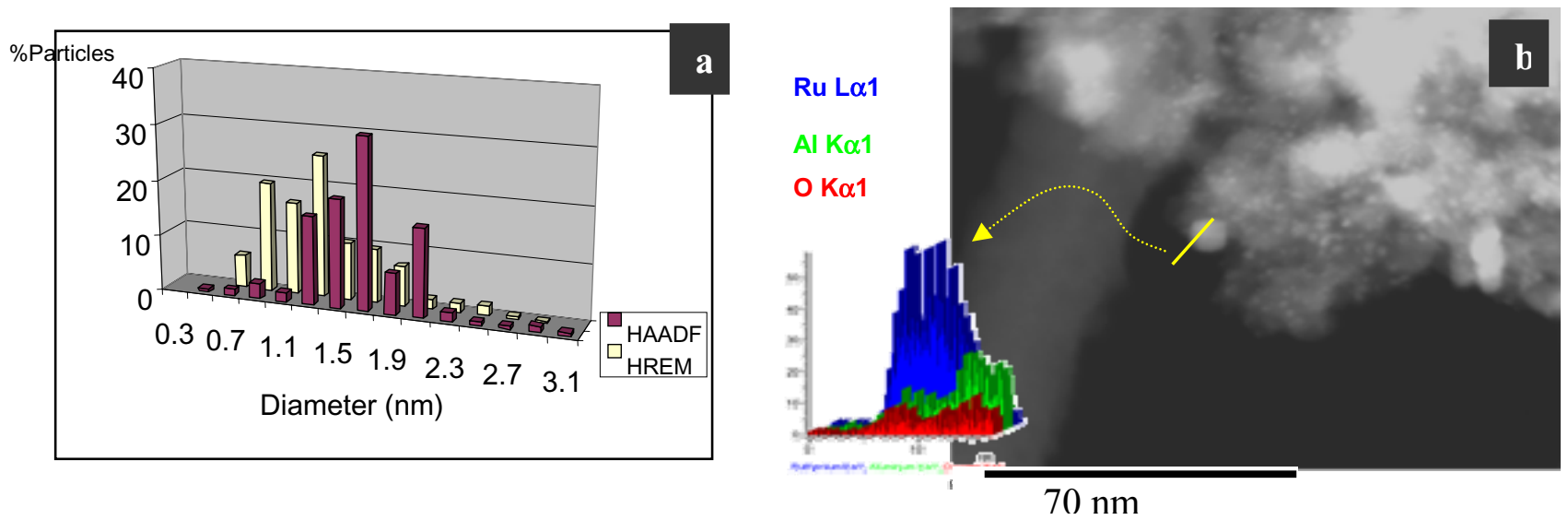

FIG. 1.a) Distribution of particles sizes for $\mathrm{Ru}-\mathrm{Al}_{2} \mathrm{O}_{3}$ after reduction at $623 \mathrm{~K}$ as established by HAADF and HREM. b) HAADF Image of $\mathrm{Ru}-\mathrm{Al}_{2} \mathrm{O}_{3}$ after reduction at $1173 \mathrm{~K}$. An X-EDS composition profile of a particle is also shown.
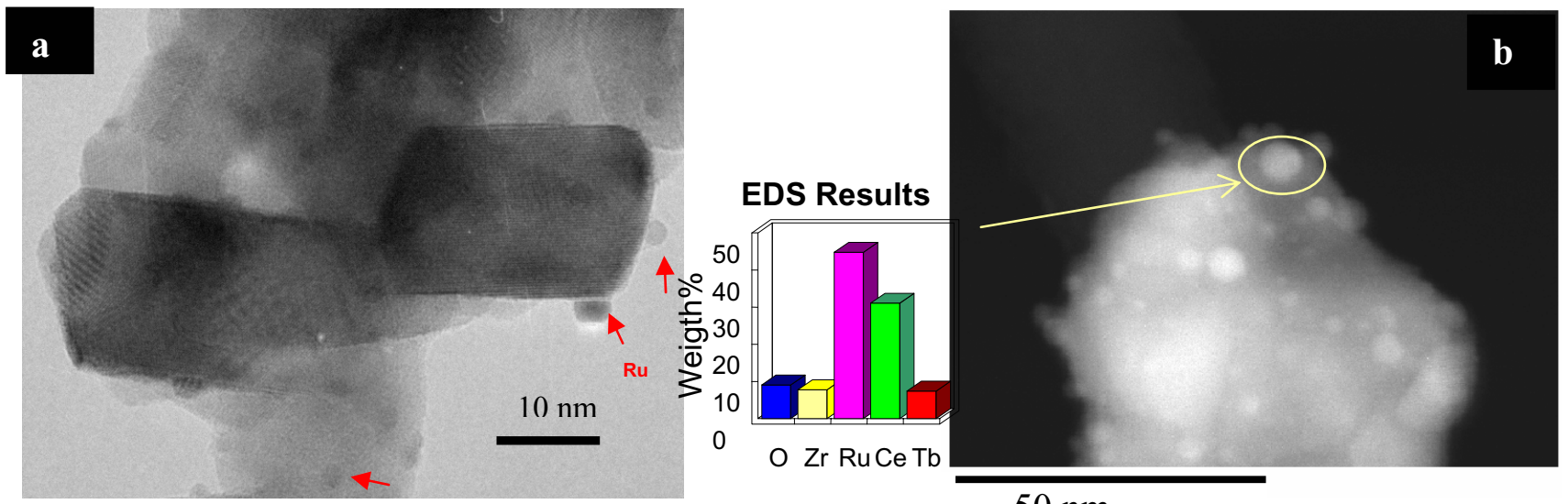

FIG. 2. HREM (a) and HAADF (b) images of $\mathrm{Ru}-\mathrm{Ce}_{0.5} \mathrm{Zr}_{0.38} \mathrm{~Tb}_{0.12} \mathrm{O}_{2}$ after reduction in $\mathrm{H}_{2}(5 \%) / \mathrm{Ar}$ at $1173 \mathrm{~K}$. The results of EDS analysis of a particle of a $\mathrm{Ru}$ particle are included. 